\title{
REIVINDICAR OS DIREITOS DAS MULHERES EM 1791: UMA TENTATIVA FADADA AO FRACASSO? O INTERDISCURSO DA DECLARAÇÃO DOS DIREITOS DA MULHER E DA CIDADÃ
}

\author{
Jurgen Siess ${ }^{\mathrm{i}}$
}

Resumo: Examinando a Declaração dos Direitos da Mulher e da Cidadã (1791), texto indefectível do feminismo, escrito por Olympe de Gouges, procuramos mostrar uma inovação radical que, paradoxalmente, ali acontece nos interdiscursos, sobretudo acerca do já-dito. Ao fazer uma releitura da Declaração dos Diretos do Homem e do Cidadão de 1789, a Cidadã De Gouges subverte o discurso que fora profundamente inspirado na obra de Rousseau. Ela enfatiza, sobretudo, os discursos femininos e girondinos, para questionar as premissas de Rousseau e dos deputados membros da Constituinte presentes na Declaração de 1789, e também para reclamar parte do poder que foi negado às mulheres.

Palavras-chave: Direitos da mulher. De Gouges. Palm d'Aelders. Interdiscurso.

\begin{abstract}
The article examines the Declaration of the Rights of Woman and [of the Female] Citizen (1791) a landmark text of feminism written by Olympe de Gouges, and argues that, paradoxically, a radical innovation is built on interdiscourse, namely, on the "already said». By resuming the Declaration of the deputies (1789), the Citizen De Gouge subverts their discourse that is deeply inspired by Rousseau's texts. She draws upon discourses of women and of the Girondins in order to call into question the premises Rousseau and the deputies start with and to claim a share in power that has been denied to women.
\end{abstract}

Keywords: Women's rights. De Gouges. Palm d'Aelders. Interdiscourse. 
EID\&A - Revista Eletrônica de Estudos Integrados em Discurso e Argumentação, Ilhéus, n. esp. ADARR, mai.2016.

\section{Introdução}

Como uma inovação radical emerge no discurso? E quão persuasiva ela chega a ser ante um auditório? Paradoxalmente, é com base nos interdiscursos, isto é, com apoio nos já-ditos, que o radicalmente novo acontece. É isso que nos propomos a mostrar, ao examinarmos de que forma os Direitos da mulher de Olympe de Gouges - cuja obra mais importante é a Declaração dos Direitos da Mulher e da Cidadã (1791) - representa, em sua época, uma reivindicação memorável, com base num processo interdiscursivo.

Aqui adotamos a noção de interdiscurso, central na análise de discurso, e que assevera: "todo discurso é atravessado pela interdiscursividade, tendo por propriedade constitutiva o fato de estar em relação multiforme com outros discursos" (CHARAUDEAU; MAINGUENEAU, 2002, p. 324). Eis a essência da definição do fenômeno que aqui reteremos:

O conjunto de unidades discursivas (sejam discursos anteriores de um mesmo gênero, sejam discursos contemporâneos de outros gêneros etc.) com os quais um discurso particular se relaciona explícita ou implicitamente. Esse interdiscurso pode apresentar unidades discursivas de dimensões bastante variáveis [... ] (CHARAUDEAU; MAINGUENEAU, 2002, p. 325).

O interdiscurso está estreitamente relacionado com a noção bakhtiniana de dialogismo, a qual sustenta que um discurso encontra necessariamente 0 discurso do outro e com ele interage. "O Adão mítico, em um discurso virgem e ainda não dito, o solitário Adão, somente ele poderia de fato evitar essa reorientação mútua e dependente do discurso do outro", escreve Bakhtin (apud TODOROV, 1981, p. 98). Tal perspectiva implica repensar a inovação, seja ela radical ou não, em sua relação intrínseca com o que se diz e com o que se pensa no momento em que se diz/pensa. Em verdade, os antigos fios com os quais se tece um novo discurso são mais ou menos identificáveis e cabe ao analista apontá-los, além de observar de que forma fios novos e antigos interagem e como são reconfigurados na produção de algo novo. A partir de uma concepção de interdiscurso como parte do discurso social em transformação, pretendo analisar as marcas do locutor-escritor, sua forma de adaptar elementos do discurso social, sua 'perspectiva' - o que Bakhtin (1970, p. 269) chama de atitude própria e julgamento de valor do locutor/locutora. É o caso, ainda, de perscrutar em que medida essa 'perspectiva' está em consonância com os objetivos e com o auditório da/o autora/a. 
EID\&A - Revista Eletrônica de Estudos Integrados em Discurso e Argumentação, Ilhéus, n. esp. ADARR, mai.2016.

1 Olympe de Gouges, autora e mulher da Revolução

A Cidadã Marie-Olympe de Gouges lê com olhos de águia os autores cujos discursos ela retrabalha, mergulhando profundamente em seus textos para inverter certas premissas e enfatizar suas próprias ideias. Aqui se fará uma leitura privilegiada da Declaração dos Direitos da Mulher e da Cidadã (1791): único texto do conjunto intitulado Os Direitos da Mulher, que se refere abertamente a um texto preexistente, a Declaração dos Direitos do Homem e do Cidadão (1789). O próprio título já remete ao texto de referência, texto consagrado que aparece como o instigador do projeto de Olympe de Gouges. No entanto, veremos que o texto de 1789 , tido como definitivo e universal, longe de constituir um exemplo a ser seguido, será um material a ser retrabalhado e subvertido. É como se a Declaração atribuída aos Constituintes da Assembleia Legislativa fosse a expressão mais flagrante dos direitos que os homens atribuíam a eles mesmos e cujo poder De Gouges pretendia neutralizar. Madame de Gouges questiona radicalmente tal pretensão, reclamando a participação das mulheres no poder do qual, aliás, elas tinham sido excluídas quando da Declaração dos deputados homens.

O texto de Madame de Gouges não para por aí. Ele reúne gêneros bastante diversos e de múltiplas instâncias, modificando e dando um outro tom ao conjunto dos textos matriz. Sem tomarmos em consideração a 'estratégia' - mais ou menos consciente - que permeia os Direitos da Mulher, não poderíamos analisar de forma satisfatória a interdiscursividade ali presente. A minha hipótese é que os discursos que ali podemos destacar, sejam eles contíguos ou distantes, encontram-se no texto reunidos e integrados em uma argumentação particular. Eu vou me deter em três planos discursivos principais e que se cruzam no texto: rousseuniano, 'feminista' e girondino. Os elementos de um discurso 'feminista', até ali dispersos em reclamações e proposições de algumas mulheres (NOACK, 1993, p. 93-4) convergem, com esse novo texto, em um programa consequente e radical. $O$ teor é politizado e busca soluções concretas. O discurso rousseaunistaconstitucional serve de base para os discursos femininos e confere à Declaração dos Direitos da Mulher e da Cidadã seu fundamento antropológico, num processo de questionamentos e subversão. Enfim, aqui destacaremos ainda o discurso de Condorcet e dos Girondinos que estão no meio do caminho entre o texto de Rousseau e de De Gouges (CHAUMIÉ 1980, p. 49 e 
EID\&A - Revista Eletrônica de Estudos Integrados em Discurso e Argumentação, Ilhéus, n. esp. ADARR, mai.2016.

seguintes)'. Mais precisamente, os discursos femininos preexistentes e 0 discurso girondino servem de apoio à subversão do discurso rousseaunista e do discurso democrático fundador (o da Declaração dos Direitos do Homem, de $1789^{2}$ ). Em vez de serem examinados separadamente, esses diferentes planos serão considerados em um estudo que, sempre que possível, acompanha passo a passo o desenvolvimento do texto.

Antes de detalharmos a análise, exporemos algumas observações sobre a autora. Graças aos estudos feministas e ao historiador Olivier Blanc, conhecemos melhor Olympe de Gouges, grande mulher da Revolução, condenada à morte pelos robespierristas por ter reclamado um lugar na tribuna, onde somente homens tinham espaço (ela foi executada em 3 de novembro de 1793). Em setembro de 1791, Madame de Gouges submete à Assembleia Nacional um texto complexo, Os Direitos da Mulher, cujo texto central é constituído pela Declaração dos Direitos da Mulher e da Cidadã, considerado hoje como divisor de águas e texto-referência da história das mulheres.

É importante destacar, para situarmos a ousadia de Olympe no contexto histórico imediato, que 1791 é o ano da fuga do casal real para Varennes (em junho); é ainda o ano da rebelião do Campo de Marte visando à queda de Louis XIV, revolta reprimida pela guarda nacional de La Fayette (em julho) e que teve fim, no começo de setembro, com o encerramento do debate pela Assembleia Nacional sobre a Constituição, um outro texto fundador da República. É este momento que, aos olhos da Cidadã, parece ter sido propício para a proposição de uma declaração à primeira vista complementar, mas em realidade alternativa, "oposta" (FRAISSE, 2000, p. 171; ANGENOT fala em "panfleto", 1977, p. 92) - na qual um programa político e jurídico vanguardista é apresentado.

\section{A disposição da declaração e do peritexto}

A disposição dos direitos da mulher é complexa. O texto é constituído de corpus em duas partes: a Declaração dos Direitos da Mulher e da Cidadã e o texto Forma do contrato social do Homem e da Mulher. A primeira parte é precedida de uma dedicatória À Rainha e começa se dirigindo ao Homem; traz

1 Mme. de Gouges manteve contato com eles, por exemplo, na Sociedade dos Amigos dos Negros (GOUGES, 1993, p. 18, 20; BLANC, 2003, p. 130).

2 Eu retomo, como o discurso da primeira Declaração, os epítetos de Marcel Gauchet (1989, p. III). 
EID\&A - Revista Eletrônica de Estudos Integrados em Discurso e Argumentação, Ilhéus, n. esp. ADARR, mai.2016.

17 artigos (igual à Declaração dos deputados homens) e a advertência "A ser decretado pela Assembleia Nacional", além do Preâmbulo e do Posfácio (este último dirigido à mulher). A segunda parte - o modelo de contrato conjugal e de parceria - apresenta, em forma de anexo, um comentário, proposições de lei e uma demonstração com exemplum. O conjunto traz ainda um P.S. que representa um afago, visto como uma crítica radical, uma reivindicação programática. No conjunto da obra, encontramos os mais diversos dispositivos de enunciação, referências ao contrato e comentários jurídicos, passando pela declaração e pela demonstração. Ali vemos como alguns gêneros são retomados e como diversos discursos são elaborados com uma orientação particular. É importante observar ainda que apenas a alusão à rainha é assinada - "de Gouges" -, como se o texto principal falasse por si ou enunciasse a convicção e a reivindicação de todas as mulheres.

O texto dirigido à Rainha - que podemos entender como um pastiche da dedicatória - projeta, como bem pretende a destinatária, a imagem da mãe da pátria que não apenas toma partido pelo povo mas também encabeça aquele movimento. Arriscamo-nos a dizer que o ethos da locutora desvela a cidadã que estende a mão à esposa do monarca para the mostrar o bom caminho a seguir, além de guiar o próprio rei nesse caminho. Tanto o exórdio quanto a conclusão lembram a eloquência simples e franca sobre a qual falava Rousseau - no início: "Pouco afeita à linguagem dos Reis" (De GOUGES, 1791, p. 204), e no final: "todo bom Cidadão sacrifica sua glória, seus interesses" (Ibidem, p. 205). Na argumentação que pretende ganhar a simpatia da primeira dama da França, vai-se da rainha aos franceses, e desses às mulheres, que são as únicas aptas a mudar a mentalidade das pessoas cujos direitos Maria Antonieta ajudará a conquistar.

O tom muda sensivelmente com o texto que introduz a Declaração dos Direitos da Mulher e da Cidadã:

Homem, você é capaz de ser justo? É uma mulher que te pergunta; você não vai privá-la de pelo menos esse direito. Diga-me? Quem te deu o poder de oprimir meu sexo? [...] examine a natureza em toda a sua grandeza [...] e me dê, se ousa, o exemplo de tamanha tirania (Ibidem, p. 205).

O questionamento é direto e de igual para igual. Observemos que, no Artigo IV, a redatora continua: "o exercício dos direitos da mulher é ilimitado, exceto pela tirania que o homem Ihe impõe" - (Ibidem, p. 207). Nessa fala 
EID\&A - Revista Eletrônica de Estudos Integrados em Discurso e Argumentação, Ilhéus, n. esp. ADARR, mai.2016.

dirigida aos homens, percebe-se a ressonância do discurso rousseaunista. 0 capítulo 3 do Livro I do Contrato Social (1972 [1762]) afirmava:

A força é um poder físico; eu não vejo de forma nenhuma qual moralidade pode resultar de seus efeitos [...], e porque o mais forte tem sempre razão, trata-se apenas de se tentar ser o mais forte. Mas qual é mesmo a relação do fim de um direito com a extinção de uma força? [...] a força não faz o direito, e [...] somos obrigados a obedecer apenas aos poderes legítimos (p. 65-66).

O argumento de Rousseau é retomado, mas radicalizado, pois o Contrato Social refere-se ao gênero humano em geral e não inclui exatamente as mulheres; ali Rousseau se refere a Adão e a outros personagens masculinos. Eva e qualquer outra figura feminina são deixadas de fora (I. 2). Madame de Gouges, ao contrário, inverte esse argumento para utilizá-lo contra os homens, em favor das mulheres. Ali vemos o interdiscurso rousseaunista quando a natureza é invocada como instância superior e declamada nos seguintes moldes: "examine a natureza em toda a sua grandeza" (DE GOUGES, 1993, p. 205-6); no entanto, a pretensão de o Homem se referir à natureza tal qual Rousseau a concebia é imediatamente colocada em questão: "grandeza da qual você parece querer se aproximar" (Ibidem, p. 205-6), e a "natureza" torna-se assim um valor mais próximo do universo das mulheres. Em todos os lugares, o homem encontrará os dois sexos "misturados" no “conjunto harmonioso" que a natureza compõe (Ibidem, p. 206). No entanto, o discurso rousseaunista é reinterpretado e reconstruído com premissas feministas ${ }^{3}$. Desse modo, podemos ali ouvir o eco do discurso igualitário que remonta à Marie de Gournay, de 1622, o qual dizia: “o animal humano não é homem nem mulher, e que fique claro, os sexos não devem constituir espécies diferentes" (GOURNAY, 1996 [1622], p. 27). Vemos, assim, como um discurso feminista é integrado à Cidadã e atua como argumento antirrousseaunista.

A natureza, considerada como instância suscetível de legitimar um discurso ao mesmo tempo interrogativo e reivindicador, permite a Madame de Gouges negar a superioridade do homem e tentar evidenciar a desigualdade de gêneros tal como ela enxergava. Antes dela, aliás, Etta Palm d'Aelders, em dezembro de 1790, diante da Sociedade dos Amigos da Verdade, exige que os homens, membros dessa sociedade, respeitem as mulheres e os seus direitos recém-adquiridos e que sejam justos com elas - "e que daqui para

3 NT: No original, temos "prémisses féminines", mas, pelo contexto, a melhor tradução nos parece "premissas feministas". 
EID\&A - Revista Eletrônica de Estudos Integrados em Discurso e Argumentação, Ilhéus, n. esp. ADARR, mai.2016.

frente sejamos suas companheiras e não suas escravas" (1971b) ${ }^{4}$. É importante destacar que o sentido de "companheira", ou aquela que coopera e convive com um homem, encontra-se também nas Propostas dirigidas à Assembleia Nacional em favor do sexo, de 1789, em que se defende a ideia de "uma igualdade perfeita" (Ibidem, p. 3). Encontramos ainda em Olympe elementos de discursos feministas anteriores.

Podemos ouvir, nessas declarações ao Homem, já no exórdio, um eco do Jornal das Damas e, então, do discurso da Madame de Beaumer (1761) e da Madame Maisonneuve (1765). No Preâmbulo de outubro de 1761, Madame de Beaumer afirma pretender vingar seu sexo dessa "ideia injuriosa da qual compartilham ainda alguns bárbaros dentre nossos cidadãos, os quais custam a permitir que as mulheres possam pensar e escrever" (p. III); ela diz ainda pretender "ensinar moderação e equidade aos cavalheiros" (p. V); em seguida, ela destaca mulheres autoras de obras científicas em pé de igualdade com os homens. Mais tarde, em outubro de 1765, Madame de Maisonneuve, nova redatora-chefe do Jornal das Damas, critica os homens por terem lançado sobre eles mesmos honrarias e liberdade, ao mesmo tempo em que tentavam fazer o mundo acreditar que as mulheres não eram pessoas brilhantes em seus talentos (ver DIACONOFF, 2005, p. 104).

Em Madame de Gouges, lemos: "ele quer agir como déspota sobre um sexo que tem todas as faculdades intelectuais" (1993, p. 206). Importante ressaltar que as referências ali são paralelas, na medida em que tanto a Mulher quanto a Cidadá atribuem-se o lugar daquela que tem conhecimento e, por isso, pode instruir o outro. Desenha-se, aqui, a figura de um sujeito feminino que reclama igualdade plena e efetiva, e nada menos.

Podemos, desse modo, já antes dos artigos da Declaração de Gouges, quando ali se faz referência ao homem, apontar um interdiscurso com várias facetas e que, na argumentação de Olympe, estão concentradas e servem como preparação de um libelo contra o homem, "degenerado", "de ignorância abjeta", reivindicando impropriamente "o direito à igualdade" (Ibidem p. 206); ali o ser feminino se apresenta de forma superior em relação a seu alocutário masculino.

4 Discours sur l'injustice des Lois en faveur des Hommes, aux dépens des femmes, lu à l'Assemblée Fédérative des Amis de la Vérité, le 30 décembre 1790 (PALM D’AELDERS, 1791b, p. 3). Em março de 1791, Mme. Palm funda uma seção feminina da Sociedade da Verdade, o primeiro clube feminino (ROUDINESCO, 1989, p. 100). No verão de 1791, Etta redige uma peça virulenta "das cidadãs francesas para a Assembleia Nacional" contra um projeto de lei sobre o adultério. 
EID\&A - Revista Eletrônica de Estudos Integrados em Discurso e Argumentação, Ilhéus, n. esp. ADARR, mai.2016.

\section{Preâmbulo}

Seguem-se a esta crítica os 17 artigos da Declaração dos Direitos da Mulher e da Cidadã (1791). Eles tomam por base o texto da Declaração dos Direitos do Homem e do Cidadão (1789) e são precedidos de uma asserção programática e de um Preâmbulo (tudo em paralelo com a Declaração de 1789). A redatora realiza, entretanto, modificações decisivas. Por duas vezes o termo "mulher" fica no lugar de "homem"; em uma ocorrência, "cidadãs" substitui "cidadãos" e, ainda, "atos do poder das mulheres e os do poder dos homens" (DE GOUGES, 1791, p. 206) substitui "atos do poder legislativo e do poder executivo" (Declaração dos Direitos do Homem e do Cidadão, 1789, preâmbulo). Ali a diferença de sexos é introduzida, e as mulheres são colocadas de igual para igual em relação aos homens; às vezes até com prioridade. A asserção "As mães, as filhas, as irmãs, representantes da nação, demandam serem constituídas em Assembleia Nacional” (DE GOUGES, 1791, p. 206) substitui "Os representantes do povo francês, constituídos em Assembleia Nacional, considerando que [...]" (Declaração dos Direitos do Homem e do Cidadão, de 1789, preâmbulo). Observemos que a redatora da nova Declaração introduz na entidade "povo" a clivagem entre o gênero feminino e o gênero masculino. Notemos ainda que o primeiro lugar é agora atribuído às mulheres, mais precisamente a uma "multiplicidade de identidades femininas", e não à mulher como abstração (FRAISSE, 2000, p. 72). Deve-se notar que a esposa fica fora da Assembleia, mas, por outro lado, a irmã aparece como uma figura nova, ao lado da mãe e da filha. Na realidade, que a esposa seja deixada de fora do espaço público tem algo de rousseuaniano. No entanto, o mais importante aqui é que a redatora retém apenas a filiação feminina, a matrilinearidade, principal característica do autor de Julie (1761) e de Emile (1762), o qual situa a mulher em relação à filiação masculina. E, ainda, Madame de Gouges prevê uma dupla Assembleia: uma constituída pelos homens e outra, pelas mulheres. E é nesse sentido que leremos no Artigo III de sua Declaração: “O princípio de toda soberania reside essencialmente na nação, que nada mais é do que a reunião da mulher e do homem" (DE GOUGES, 1993, p. 207) 5 . Ali a oração subordinada representa o acréscimo feito por Olympe e por meio do qual este artigo se distingue

5 Aqui divirjo de Erica Harth, a qual afirma que o Artigo III revela que: "a família era o prisma por meio do qual De Gouges visualizava a instituição de direitos iguais". No original: "the family was the prism through which de Gouges envisioned the institution of equal rights" (1992, p. 218). 
EID\&A - Revista Eletrônica de Estudos Integrados em Discurso e Argumentação, Ilhéus, n. esp. ADARR, mai.2016.

radicalmente da Declaração dos Direitos do Homem e do Cidadão (1789). Neste contexto, uma vez mais, a diferença de sexos é marcada.

A redatora do Preâmbulo deixa claro que a nova Declaração é necessária para garantir às mulheres direitos iguais aos dos homens e instaurar um "poder feminino" como contraponto ao do sexo oposto. O Preâmbulo conclui que "o sexo superior, belo e corajoso mesmo nas dores maternas, reconhece e declara, na presença e sob os auspícios do Ser supremo, os Direitos da Mulher e da Cidadã" (DE GOUGES, 1791, p. 206). Notamos, na referência às qualidades que distinguem a mulher do homem, a alusão à natureza, o que reforça o teor argumentativo do texto. Tal qualificação não está, entretanto, livre de ambiguidade, uma vez que contrasta com o tom solene das afirmações precedentes. O epíteto "superior" - e que vem após o forte argumento da igualdade - aparece ali como uma hipérbole. A locutora procura jogar com dois registros, o sério e o lúdico. Desse modo, ela talvez pretenda evitar uma rejeição à sua audaciosa reivindicação. Essa premonição parece também explicar a invocação de uma instância concebida como superior a ambos os sexos: por mais audaciosa que seja, a reivindicação precisa ser ouvida pelos homens que também estão sob os auspícios do "Ser supremo". Tais considerações 'estratégicas' parecem ajudar a atingir o alvo.

As alusões que compõem a argumentação do Preâmbulo são de ordem antropológica: a demanda da Mulher fundamenta-se em seus "direitos naturais, inalienáveis e sagrados" (mulher fica no lugar de homem na Declaração de 1789); as mulheres, assim como os homens, receberam da natureza (que parece ser imaginada como legislador ordinário) os direitos que são, desse modo, anteriores a todo poder. E esse poder - tanto o das mulheres quanto o dos homens - erige-se (ou deve erigir-se) com base nesse mesmo fundamento (DE GOUGES, 1791, p. 206). A importância do argumento da "natureza", aliás, foi herdada de Rousseau (NOACK, 1993, p. 98). Mais precisamente, a dimensão antropológica do Preâmbulo remete ao Discurso sobre a origem $e$ os fundamentos da desigualdade entre os homens (ROUSSEAU, 1755), e é a este que se refere explicitamente outro texto anterior de Olympe de Gouges, A felicidade primitiva do homem 6 . Sabemos que Rousseau contrapõe à sociedade civil um estado Natural, no qual não há nem poder nem violência, em que a terra e seus frutos são compartilhados por todos, de forma igualitária. A Natureza "que não mente nunca" (ROUSSEAU,

6 In. DE GOUGES, Marie-Olympe. CEuvres. Paris : Mercure de France, 1986. 
EID\&A - Revista Eletrônica de Estudos Integrados em Discurso e Argumentação, Ilhéus, n. esp. ADARR, mai.2016.

1755, p. 8) torna-se a medida para todas as coisas, e os únicos direitos incontestáveis são os que nela se inscrevem; e entre tais direitos a igualdade tem um lugar de destaque ${ }^{7}$. Veremos, assim, que a Cidadã, como seu predecessor, estabelece um laço estreito entre antropologia e política. No entanto, e retomando o argumento de Rousseau, o seu texto distingue-se radicalmente dos escritos rousseaunianos, não apenas na conclusão mas também na orientação argumentativa geral do texto.

\section{Os artigos da Declaração dos Direitos da Mulher e da Cidadã}

É importante lembrar que o texto da Declaração dos Direitos da Mulher e da Cidadã (1791), ao se apresentar como intertexto da Declaração (1789) dos deputados homens, retoma-a para, em seguida, subvertê-la, com a ajuda de outros discursos, todos revisitados e reorientados num sentido radicalmente diferente. Neste texto central, encontramos ainda importantes elementos do discurso rousseaunista (que a Declaração de 1789 já integrara em parte, conforme GAUCHET, 1989, introdução e p.117-118). Desse modo, o artigo VI retoma (como no texto original) o conceito de "vontade geral" já presente no Do Contrato Social (1972 [1762]). E o artigo IV é crucial na questão do interdiscurso rousseaunista:

A liberdade e a justiça têm como função devolver tudo o que pertence ao outro; desse modo, o exercício dos direitos naturais da mulher tem como únicas barreiras a tirania perpétua dos homens, e tais barreiras precisam ser revistas pelas leis da natureza e da razão (Ibidem, p. 207).

A proposição com valor conclusivo ("desse modo, o exercício dos direitos..." - DE GOUGES, 1791, artigo IV) substitui a asserção do mesmo artigo IV da Declaração dos Direitos do Homem e do Cidadão, de 1789: "desse modo, o exercício dos direitos naturais de cada homem tem como únicas barreiras as que asseguram aos outros membros da sociedade o gozo dos mesmos direitos". Novamente (como no Preâmbulo), a redatora apresenta uma divisão entre gênero feminino e gênero masculino. $E$ mais, aqui as mulheres são colocadas em destaque como sujeitos de direito. E não se trata de seres humanos em geral, pois o que está em jogo ali é a relação de poder entre

7 Como mostra Marcel Gauchet (1989), a premissa segundo a qual o ser humano detém os direitos da natureza já era questionada por Crénière: não se deve "supor que ao homem pertençam direitos que cabem na verdade ao cidadão" (Ibidem, p. 78). Olympe de Gouges parece mais próxima do adversário de Crénière, o abade Sieyès: para ele, "o estado político constitui mero prolongamento instrumental do estado natural” (Ibidem, p. 79). 
EID\&A - Revista Eletrônica de Estudos Integrados em Discurso e Argumentação, Ilhéus, n. esp. ADARR, mai.2016.

homens e mulheres, na qual os homens aparecem como espoliadores das mulheres e de sua parte do poder a que - aos olhos da Cidadã - por natureza as mulheres têm direito.

A natureza e, com ela, a razão fundam a legitimidade dos argumentos ali empregados; juntas (natureza e razão) surgem de alguma forma como um legislador de dupla face (a face da natureza em primeiro lugar, aqui e no artigo $\mathrm{V}^{8}$, e exclusiva no Preâmbulo e no artigo XVII ${ }^{9}$, da Declaração dos Direitos da Mulher e da Cidadã, 1791). A noção rousseaunista de natureza é entretanto adaptada em um sentido particular, uma vez que o discurso intertextualizado é subvertido ao ponto de se voltar contra o próprio Rousseau, como observou Ruth Graham $(1976)^{10}$. Nesta versão, é a mulher quem ocupa o lugar legítimo por natureza, enquanto o homem não; o lugar por ele ocupado se deve ao uso da força, a um ato tirânico, responsável pela mudança de um estado natural para um mundo de regras civis. $O$ artigo IV deixa subentender que o direito que reclamavam as mulheres é superior ao dos homens. Segundo a autora, o direito desses seria contra a natureza, por se apoiar apenas no 'direito' do mais forte. Ali a premissa de Rousseau é adaptada e remodelada para atender às intenções pró-feministas. Desse modo, o direito natural da igualdade é radicalizado e reapropriado em favor das mulheres, ao contrário do que se tem no Discurso da Desigualdade e no Contrato Social, nos quais o autor referiase apenas aos homens.

A Cidadã De Gouges muito provavelmente retoma aqui, de um texto de Etta Palm d'Aelders, de julho de 1791, Adresse des Citoyennes françaises à l'Assemblée nationale (1791a), uma crítica ao artigo XIII do Código de Polícia (que previa penas duríssimas para as mulheres adúlteras). "Por muito tempo a tirania mais odiosa se dedicou a leis absurdas” (PALM D'AELDERS, 1791a, p. 38), denuncia Madame Palm; para ela, esse projeto de lei constitui "um refinamento do despotismo" (Ibidem p. 38). Ela questiona os deputados: "Os senhores seriam capazes de punir com tanta veemência a quem cuida dos tesouros da pátria?" (Ibidem, p. 38) e ruma à conclusão de sua fala com a seguinte exigência: "Os senhores finalizarão sua obra atribuindo às mulheres uma educação moral igual à de seus irmãos" (Ibidem p. 38), seguida da

8 A expressão "as leis da natureza e da razão" substitui, na nova Declaração de DE GOUGES (1791), "A lei" (da Declaração dos deputados homens, 1789).

9 Aqui ainda a redatora introduz a relação entre os dois sexos ("As propriedades são reunidas ou separadas para todos os sexos [...]").

10 Apesar de substancial, esse capítulo de Graham é pouco utilizado pelos pesquisadores franceses. 
EID\&A - Revista Eletrônica de Estudos Integrados em Discurso e Argumentação, Ilhéus, n. esp. ADARR, mai.2016.

asserção: "A natureza nos quer iguais, companheiros e amigos" (Ibidem, p. 40). Enquanto a fala de Etta Palm é rica em pathos (referindo-se à história romana), Olympe de Gouges utiliza os termos matter of $f_{a c t}{ }^{11}$, ao reclamar o direito natural, anterior mesmo à História ${ }^{12}$.

Analisemos rapidamente, nos artigos da Declaração dos Direitos da Mulher (1791), o elemento "igualdade". Até o artigo VI, a igualdade é concebida como um princípio positivo. $\mathrm{O}$ artigo I preconiza a igualdade dos sexos, e o artigo VI concretiza esse princípio juridicamente: "todas as cidadãs e todos os cidadãos [...] devem ser tratados de forma equânime e digna, em lugares e empregos públicos" (DE GOUGES, 1791, p. 207). Na Declaração dos Direitos do Homem e do Cidadão, de 1789, o grupo nominal-sujeito é "Todos os cidadãos". A partir do momento em que ela passa à dimensão política e jurídica, Madame de Gouges se distancia dessa Declaração e também de Rousseau, o qual havia reintroduzido a desigualdade, quando o assunto era a diferença entre os sexos. No discurso rousseaunista, o espaço público é reservado ao homem. Em seu Emílio ou Da educação (1914 [1762]), pode-se observar que a mulher cuida da casa, e o homem, da cidade (ROUSSEAU, 1914 [1762], p. 206; FRAISSE, 1995, p. 200-201).

A qualificação muda nos artigos VII, IX, X e XIII, na Declaração de De Gouges (1791). Pode-se mesmo falar em igualdade negativa cujo ponto culminante é alcançado em IX: "Tendo sido a mulher declarada culpada, a lei agirá com rigor", em vez de: "Tendo sido o homem presumido inocente [...], não há por que excesso de rigor" (GAUCHET, 1989, p. II). Se a Cidadã vai mais longe do que a Declaração de 1789, não podemos perder de vista algumas considerações 'estratégicas'. Muito já se escreveu sobre o artigo X (DE GOUGES, 1791), que assevera: "se a mulher tem o direito à pena capital, ela deve também ter o direito à defesa": eis o acréscimo que Madame de Gouges introduz (em comparação com o texto da Declaração dos Direitos do Homem e do Cidadão, 1789), após buscar assegurar a liberdade de opinião. Ali se tem um ato de opressão - a aplicação da pena capital - seguido de um ato de liberdade. Paradoxalmente, o que é apresentado como um direito é, na verdade (e cabe aqui destacar a ironia), um dever cruelmente imposto, o qual acaba por se tornar um argumento forte a favor de um direito capital - a liberdade de fala, o acesso ao espaço público. A ironia parece ainda ter uma

11 "Questão de fato".

12 Etta e Olympe desfilaram juntas em 14 de julho de 1792, mas muito provavelmente já tinham se cruzado em eventos políticos (BLANC, 2003, p. 127). 
EID\&A - Revista Eletrônica de Estudos Integrados em Discurso e Argumentação, Ilhéus, n. esp. ADARR, mai.2016.

explicação devido ao gap entre a reivindicação audaciosa e a forma como a redatora será julgada por tamanha ousadia. O paradoxo implica, entretanto, um elemento de crítica visando aos homens: antes de pensar (ou melhor, no lugar de pensar) em permitir às mulheres o direito à fala na Assembleia, eles pensaram em lhes dar o direito à pena de morte.

A igualdade é assim concebida numa acepção radical. Madame de Gouges defende duas assembleias, dois poderes complementares, harmonizados um no outro, suscetíveis de garantirem perfeita igualdade. Radicalizando as ideias de Rousseau, Olympe toma suas palavras de forma mais literal e atribui também às mulheres poder equivalente ao dos homens; ela emprega os "Princípios do direito político" (primeiro título do Contrato Social) a partir da diferença de sexos, que viria em primeiro lugar. Há ainda uma distinção do segundo Discurso de Rousseau, segundo o qual a desigualdade era devida à instituição da propriedade. Para Madame de Gouges, a desigualdade teria sua origem não devido à ingerência de um estado Natural (l'état de Nature), que deixou terra para todos, sem distinção, mas a atos políticos contundentes - $\mathrm{o}$ ato político fundador, de alguma forma - perpetrado por um sexo contra o outro, num golpe pesado dos homens contra as mulheres. A relação entre os sexos é concebida como uma relação harmoniosa e igualitária a princípio, mas que descambou em uma relação de hierarquia que lesa as mulheres em detrimento dos homens. $\mathrm{O}$ artigo IV, desse modo, busca atribuir às mulheres seus direitos lesados, restituindo-lhes ainda seu patrimônio ${ }^{13}$. Assim, a premissa (tida como infalsificável) de que há apenas igualdade radical é exemplificada nos 17 artigos e nas proposições de lei apresentadas, as quais buscaram preparar o terreno para a restituição dos direitos das mulheres "por meio da educação nacional, pela restauração dos costumes e pelas convenções conjugais” (DE GOUGES, 1791, p. 211).

\section{O Posfácio}

O Posfácio começa por um efusivo apelo às mulheres para que abram os olhos e exijam seu patrimônio. "O homem escravo multiplicou suas forças e precisou de ajuda para quebrar suas correntes. Livre, tornou-se um tirano para sua companheira" - "o homem compra [a mulher] como se compravam

13 Já em Mirabeau aux Champs-Elysées, Olympe de Gouges chega a dizer a Mme. Deshoulières que a questão era basicamente as mulheres conseguirem "regenerar também seu império" (1791, p. 125). 
EID\&A - Revista Eletrônica de Estudos Integrados em Discurso e Argumentação, Ilhéus, n. esp. ADARR, mai.2016.

escravos africanos" (DE GOUGES, 1993, p. 209-210). O Posfácio termina numa tomada de posição contra a desigualdade nas leis de herança e ainda contra $\mathrm{o}$ casamento. Acerca do casamento, propõe-se um projeto de contrato entre duas pessoas ("Contrato social entre um homem e uma mulher" - Declaração dos Direitos da Mulher e da Cidadã, 1791), no qual se demandam mais igualdade e mesmos direitos em matéria de divórcio. Nesse momento, escutamos, uma vez mais, ecos do texto Adresse des Citoyennes de Madame Palm: "Você escravizaria quem contribuiu para torná-lo livre" (1791a, p. 38-39). As leis que são apresentadas como potencial ameaça às mulheres são vistas por Madame de Gouges como fatos já consumados e contra os quais as mulheres precisam reagir. Seu projeto vai mais longe: a metáfora do casamento como "túmulo do amor" conclama, na verdade, a possibilidade de união livre.

Pudemos observar que o discurso rousseaunista é tomado ao pé da letra quando o assunto é igualdade: a Cidadã De Gouges reclama tratamento igualitário para a mulher, incluindo aí a sua inserção no espaço público. Os elementos interdiscursivos que, num primeiro momento, parecem dar um passo em direção aos escritos de Rousseau são, na verdade, ambíguos; muito ambíguos, pois, Madame de Gouges, ao retomar as ideias do filósofo, subverte-as, voltando contra ele próprio a premissa da igualdade. Para a escritora, Rousseau enclausurou as mulheres no espaço privado, enquanto ela pretende libertá-las. Nesse momento de subversão argumentativa do texto de Rousseau, enxergam-se interdiscursivamente os textos Egalité des Hommes et des Femmes de Gournay (1996 [1622]) e Motions en Faveur du Sexe e também outros textos de Etta Palm d'Aelders.

\section{Um interdiscurso complexo}

O interdiscurso presente em Os Direitos da mulher é muito mais complexo do que se pensa. Em verdade, muitos discursos anteriores confluem para o texto de Olympe de Gouges, a qual os trata de uma forma toda particular. Vejamos o discurso da igualdade, pró-feminista, de Condorcet e de seus adeptos, bem conhecido por De Gouges. Para Condorcet, a igualdade era primordial. Ele reconhece absolutamente as mesmas qualidades para todos os seres humanos "independentemente de religião, cor ou sexo" (CONDORCET et al., 1989, p. 54). Em resumo, pretende-se que todos tenham os mesmos direitos (CONDORCET et al., Ibidem, p. 54; CHAUMIÉ, 1980, p. 37, 50-51). Os girondinos próximos de Condorcet, como Brissol e Lanthenas, Rouzet e 
EID\&A - Revista Eletrônica de Estudos Integrados em Discurso e Argumentação, Ilhéus, n. esp. ADARR, mai.2016.

Guyomar, partilham dessa linha argumentativa e também propugnam a igualdade entre os sexos. O célebre matemático e filósofo que, desde o começo, participa dos debates e dos trabalhos acerca da Constituição é um defensor das mulheres desde 1787. Já em Lettre d'un Bourgeois de New Haven à un citoyen de Virginie (1847-1849), Condorcet distingue-se de Rousseau, que recusa às mulheres a igualdade política (BADINTER e BADINTER, 1988, p. 229). Em julho de 1790, surge seu artigo programático "Sur l'admission des femmes au droit de cité" (1840 [1790]), o que só veio a dar mais ênfase à gritante omissão desse tema na Declaração dos Direitos do Homem e do Cidadão (1789): filósofos e legisladores violaram o princípio da igualdade dos direitos naturais ao excluírem as mulheres; e isso foi visto como um "ato de tirania". Condorcet se empenha em refutar argumentos antifeministas, utilizando-se de exemplos históricos. Com base nos fatos, pergunta: "Por que seres expostos a gravidezes e a indisposições passageiras não poderiam gozar de direitos dos quais jamais ousamos privar as pessoas afetadas pela gota durante o inverno mas que ficam gripadas facilmente?" (CONDORCET et al., 1989, p. 54) Condorcet raciocina focando nos direitos apenas, podendo concluir que não apenas as qualidades das mulheres e dos homens, mas também as diferenças que os distinguem (lacunas, barreiras etc.) são equivalentes, e o direito (droit de cité) não deve prestigiar nenhum sexo em detrimento do outro; igualdade perante a lei (FRAISSE, 1995, p. 197). Em um discurso publicado em janeiro de 1791, ele, numa fala empolgada, acrescenta que as mulheres, ao contrário dos homens, parecem ser mais dotadas da "verdadeira coragem que engrandece a alma e que a torna capaz de grandes feitos" (CONDORCET et al., 1989, p. 64).

Pudemos assim observar como os três grandes planos discursivos funcionam neste complexo texto; como os Direitos da Mulher integram os discursos 'feministas', rousseaunista e girondino. Concluiremos que a Declaração dos Direitos da Mulher e da Cidadã é, com seus anexos, uma tentativa de reequilibrar o poder que os homens, até a Constituinte (la Constituante), reservaram a eles próprios. E isso acontece por meio de reflexões políticas e de proposições jurídicas bastante concretas (como em matérias de divórcio e de sucessão), em que as mulheres devem adquirir o conhecimento necessário para a defesa dos seus interesses. Para a locutora-

14 Também os detratores fundamentavam-se na natureza, afirmando que essa é quem tinha reservado o espaço privado à mulher e que, ao adentrar o espaço público, a mulher se desviava de sua vocação natural, a qual consistia em cuidar das crianças e da casa (BADINTER e BADINTER, 1988 , p. 18). A referência à natureza servia naquele contexto a induzir não um direito mas um dever e, mais, tal dever deveria justificar precisamente a recusa de conceder um direito fundamental. 
EID\&A - Revista Eletrônica de Estudos Integrados em Discurso e Argumentação, Ilhéus, n. esp. ADARR, mai.2016.

redatora, trata-se de restituir às mulheres a parte legítima que lhes fora privada pelos homens, numa tentativa de permitir a elas o usufruto pleno dos direitos fundamentais. E mais: esse texto busca conquistar, em nome de todas as mulheres - e com elas -, o acesso ao espaço público.

Ao reivindicar o acesso ao espaço público em pé de igualdade com os homens, a Cidadã De Gouges busca se posicionar no campo político da época. Os discursos retomados e modificados em proveito de um projeto 'feminista' pretendem servir de apoio a tal reivindicação e à realização de tal projeto. Qual seria a contribuição de Olympe de Gouges? Como ela se situa em relação a outras mulheres com aspirações parecidas? Posso esboçar apenas os primeiros elementos para uma resposta. Madame de Gouge tenta autolegitimar-se como cidadã que utiliza a pena em serviço da Revolução. Essa tentativa é necessária porque o papel da mulher-autora-política não estava previsto. Veremos em que medida seu apelo ao direito de publicação de seus textos políticos eram plausíveis.

Contrariamente à Théroigne de Méricourt ou Claire Lacombe, Olympe de Gouges não busca atividades políticas espetaculares. Se ela frequenta os salões ou se ela apresenta um pedido à Assembleia, se ela recita uma homenagem a Mirabeau no café Procópio ou se é destaque em uma festa revolucionária (em 3 de junho de 1792), sua principal forma de atuação é por meio da escrita, manifestos, opinião, projetos de lei. Desse modo, ela pretende não apenas participar do debate democrático, mas o instaurar como prática efetiva. Trata-se de propiciar às mulheres os argumentos que lhes faltam. Ela pretende confrontar os homens com os argumentos que eles evitam ou ignoram, buscando estabelecer, assim, uma nova relação entre 0 povo, seus representantes e o rei/rainha (até o mês de junho 1792, data que Madame de Gouges abandona definitivamente o casal real e a ideia de monarquia constitucional). Em cada um dos seus textos, a Cidadã De Gouges procura defender e reafirmar seu direito à fala: cada carta aberta, cada discurso, cada projeto procura avivar a reivindicação das mulheres, qual seja: "subir a tribuna". E esse é o seu principal traço distintivo, isto é, dar o exemplo a outras mulheres para que elas possam acessar o campo político. É importante lembrarmos que essa é apenas uma faceta de sua luta. $O$ outro traço importante é a função determinante que ela atribui à diferença de sexos. Olympe parece considerar que a luta política não era meramente 'atravessada' pela diferença de sexos; ela entendia que tal diferença era, na verdade, 
EID\&A - Revista Eletrônica de Estudos Integrados em Discurso e Argumentação, Ilhéus, n. esp. ADARR, mai.2016.

determinante no combate travado pelos diversos grupos e camadas sociais para chegarem a um poder e a uma organização social fundados na liberdade e na igualdade.

Seria interessante confrontar a Declaração dos Direitos da Mulher e da Cidadã (1791) com a Requête des Dames (1789), uma petição que já clamava pela igualdade dos sexos mesmo em cargos mais elevados. Ao contrário de Madame de Gouges, os autores da Requête utilizam o tratamento "Nosseigneurs"15 (que não se dirigia especificamente ao "Homem") e solicitam a igualdade de participação nos trabalhos da Assembleia Constituinte "como os/as senhores/as \& com os/as senhores/as" (Requête des dames, à l'Assemblee Nationale, 179?).

Quanto a Olympe de Gouges, diríamos que a autolegitimação destinada a Ihe permitir a obtenção de uma posição no espaço público está fadada ao fracasso: ela não poderá ocupar nenhum lugar no campo político. Se suas tentativas de retomada de discursos anteriores é crucial, a adaptação desses textos nem sempre se mostra muito eficaz; pelo menos não mais do que a sua própria iniciativa de reescrevê-los. Subverter o discurso rousseaunista ao ponto de apontá-lo contra o seu próprio autor pode ter parecido um sacrilégio, e não apenas aos olhos dos deputados da Constituinte que consideravam Rousseau como o grande guia. Há, sobretudo, as resistências dos homens que não estão nem um pouco a fim de ceder um milímetro de sua parcela de poder, apesar de todo o corajoso esforço da Cidadã De Gouges e de todos os argumentos por ela defendidos com bravura. Os robespierristas devem ter encarado a Declaração dos Direitos da Mulher e da Cidadã como uma afronta, uma vez que esse libelo desafia um texto já consagrado e que tinha sido escrito por (e para) homens. Em 1793 - enquanto ela atacava Robespierre -, dá-se um embate mortal entre eles, numa luta de sexos em que os homens estão massivamente em vantagem. Olympe de Gouges, moderada até certo ponto, é radical quando se trata de comparação entre os sexos: ela luta pela igualdade legitimada pela natureza e pela razão ${ }^{16}$. Moderada em política (ela defende por muito tempo a monarquia constitucional), radical na sua forma

15 NT: uma espécie de tratamento geral dirigido a nobres de diferentes ordens (eclesiásticos, cortesãos etc.).

16 "Se ela admite que a monarquia fabrica tiranos, por outro lado ela não defende a queda da coroa"; pronta a "aceitar leis republicanas", ela ratifica, entretanto, a ação dos Constituintes (SOPRANI, 1988, p. 94). 
EID\&A - Revista Eletrônica de Estudos Integrados em Discurso e Argumentação, Ilhéus, n. esp. ADARR, mai.2016.

de compreender a relação entre homens e mulheres, ela estava duplamente marginalizada.

\section{Concluindo}

Retornemos rapidamente ao retrabalho a que a Cidadã submete a Declaração dos Direitos do Homem e do Cidadão: tal revisita serve, em grande parte, para subverter o texto original (isto é, a Declaração dos Direitos do Homem e do Cidadão, de 1789), em que a palavra mulher fica no lugar de homem ou ainda introduzindo uma clivagem em termos genéricos como Povo ou Nação. As retomadas realizadas no texto de referência pretendem ressaltar o que ali está invisibilizado: a diferença de sexos e, mais precisamente, a relação de poder entre os homens e as mulheres. A releitura feita por Olympe de Gouges mostra como os empréstimos ou referências a outros textos e outros discursos podem colocar em xeque - e mesmo inverter - o sentido que o público deveria encontrar no texto original.

A Declaração dos Direitos da Mulher e da Cidadã obtém êxito ao retomar o discurso rousseaunista e a Declaração dos deputados homens para, em seguida, subvertê-los e confrontá-los com discursos 'feministas' e girondinos, os quais serviram de apoio para tais subversões. Sabemos que esse texto, radicalmente inovador, não teve boa acolhida em sua época. Foi necessário esperar o Movimento de Libertação das Mulheres para que finalmente o documento tivesse justo reconhecimento.

\section{Referências}

ANGENOT, M. Les champions des femmes. Montréal : P. U. du Québec, 1977.

BADINTER, E.; BADINTER, R. B. Condorcet. Un intellectuel en politique. Paris : Fayard, 1988.

BAKHTINE M. La poétique de Dostoïevski. Paris: Seuil, 1970.

BLANC, O. Marie-Olympe de Gouges. Une humaniste à la fin du $18^{\mathrm{e}}$ siècle. $\mathrm{s} / \mathrm{l}$ : Editions René Viénet, 2003.

CHARAUDEAU, P.; MAINGUENEAU, D. Dictionnaire de l'Analyse du Discours. Paris: Seuil, 2002.

CHAUMIÉ, J. Les Girondistes. In. SOBOUL, A. (dir.). Girondistes et Montagnards. Paris : Société des Etudes Robespierristes, 19-60, 1980. 
EID\&A - Revista Eletrônica de Estudos Integrados em Discurso e Argumentação, Ilhéus, n. esp. ADARR, mai.2016.

CONDORCET; PRUDHOMME; GUYOMAR. Paroles d'hommes (1790-1793). Paris: P.O.L., 1989.

CONDORCET. Lettre d'un Bourgeois de New Haven à un citoyen de Virginie In. CEuvres, t. IX. Paris: Arago et O'Connor, 1847-1849.

. Sur l'admission des femmes au droit de cité (1790). Firmin Didot Frères: Paris, 1847.

Déclaration des Droits de l'Homme et du Citoyen, 1789. Disponível em: https://www.legifrance.gouv.fr/Droit-francais/Constitution/Declaration-des-Droits-deI-Homme-et-du-Citoyen-de-1789. Acesso: 10 nov. 2015.

DE GOUGES, M.-O. Ecrits politiques 1788-1791. Paris : Côté-Femmes, 1993.

. Déclaration des Droits de la Femme et de la Citoyenne (1791). In. CEuvres.

Paris : Mercure de France, 1986. Disponível em: https://fr.wikisource.org/wiki/D\%C3\%Agclaration_des_droits_de_la_femme_et_de_la_ citoyenne.

. Cuvres. Paris : Mercure de France, 1986.

. Mirabeau aux Champs-Elysées. Comédie en un acte et en prose. Paris: Garnéry, 1791.

DIACONOFF, S. Through the Reading Glass: Women, Books, and Sex in the French Enlightenment. Albany: State University of New York Press, 2005.

FRAISSE, G. Muse de la Raison. Démocratie et exclusion des femmes en France. Paris : Gallimard, 1995.

. Les deux gouvernements: la famille et la Cité. Paris : Gallimard, 2000.

GAUCHET, M. La Révolution des droits de l'homme. Paris : Gallimard, 1989.

GOURNAY, M. de. Grief des dames suivi de Egalité des hommes et des femmes (s/l : Mille et Une Nuits, 1996 [1622].

GRAHAM, R. Rousseau's Sexism Revolutionized. In. FRITZ, Paul; MORTON, Richard. Woman in the Eighteenth Century and Other Essays. Toronto: Hakkert, 1976.

HARTH, E. Cartesian Women. Versions and Subversions of Rational Discourse in the Old Regime. Ithaka \& London: Cornell U. P., 1992.

Journal des Dames. Paris: Cuissart, 1761 et 1765.

MADAME DE BEAUMER (réd.). Journal des Dames. Paris: Cuissart, 1761. 
EID\&A - Revista Eletrônica de Estudos Integrados em Discurso e Argumentação, Ilhéus, n. esp. ADARR, mai.2016.

MADAME DE MAISONNEUVE, C-M.(réd). Journal des Dames. Paris: Cuissart, 1765.

MATHIEZ, A. Le Club des Cordeliers. Réimpr. Genève : Slatkine, 1975 [1910].

Motions adressées à l'Assemblée nationale en faveur du sexe. Paris: Impr. Delaguette, 1789.

NOACK, P. Olympe de Gouges. Courtisane et militante des droits de la femme. Paris : de Fallois, 1993.

PALM D'AELDERS, E. Adresse des Citoyennes françaises à l'Assemblée nationale. In. PALM D'AELDERS, E. Discours. Caen : Chalopin, 1791 .

. Discours sur l'injustice des Lois en faveurs des Hommes, au dépend des Femmes, lu à l'Assemblée Fédérative des amis de la vérité (le 30 décembre 1790). In. - Appel aux françaises sur la régénération des mœurs, et nécessité de l'influence des femmes dans un gouvernement libre. Paris: Impr. du Cercle Social, $1791 b$.

Requête des dames, à l'Assemblée Nationale. Bibliothèque Nationale de France, 179?. Disponível em: http://gallica.bnf.fr/ark:/12148/bpt6k426587.r. Acesso: 10 out. 2015.

ROUDINESCO, E. Théroigne de Méricourt. Paris : Seuil, 1989.

ROUSSEAU, J.-J.. Discours sur l'origine et les fondements de l'inégalité parmi les hommes. Amsterdam : Rey, 1755.

. Du contrat social ou principes du droit politiques ( $F$. Angué et al., éd.). Paris : Bordas, 1972 [1762].

. Emile, ou de l’Education. (Henri Legrand, éd.). Paris: Larousse, 1914 [1762].

. Julie, ou la nouvelle Héloïse. Amsterdan: Marc Michel-Rey, 1761.

SOPRANI, A. La Révolution et les femmes de 1789 à 1796. Paris : M. A. Editions, 1988.

TODOROV, T.. Mikhaïl Bakhtine, le principe dialogique. Paris : Seuil, 1981.

Como citar:

SIESS, Jürgen. Reivindicar os direitos das mulheres em 1791: uma tentativa fadada ao fracasso? O interdiscurso da Declaração dos direitos da mulher e da cidadã. Trad. Rubens Damasceno Morais. EID\&A - Revista Eletrônica de Estudos Integrados em Discurso e Argumentação, Ilhéus, n. esp. ADARR, p. 142-161, mai.2016. 